The Bangladesh Veterinarian (2018) 35(1\&2): 1 - 6

\title{
Comparative suitability of the feathers, peripheral blood and spleen tissue samples of chickens for the detection of Marek's disease virus by polymerase chain reaction
}

\author{
MW Rahman, M Nooruzzaman, US Suma, EH Chowdhury and MR Islam* \\ Department of Pathology, Faculty of Veterinary Science, Bangladesh Agricultural \\ University, Mymensingh-2202, Bangladesh
}

\begin{abstract}
A total of 24 clinical specimens (10 feathers, 8 peripheral bloods and 6 spleens) were collected from 10 suspected outbreaks of Marek's disease (MD) from Mymensingh, Tangail, Gazipur and Pabna districts of Bangladesh. A polymerase chain reaction (PCR) protocol originally described by Silva (1992) was adopted to detect Marek's disease virus (MDV) genome in these specimens. All the tested peripheral blood buffy coat samples $(100 \%)$ were positive for MDV in PCR, while $70 \%$ of feather samples and $66.6 \%$ of spleen samples were positive. A band of $317 \mathrm{bp}$ size was found in all positive samples. A few samples also yielded additional bands of $185 \mathrm{bp}$ size and/or multiple bands of larger than $317 \mathrm{bp}$ size, indicating the presence of both virulent MDV and the vaccine virus. The study suggests that peripheral blood and feathers from live birds, and feathers from dead birds are the samples of choice for the detection of MDV by PCR. (Bangl. vet. 2018. Vol. 35, No. $1 \& 2,1-6)$
\end{abstract}

\section{Introduction}

Marek's disease (MD) is a complex, immunosuppressive disease characterized by paralysis, chronic wasting, lymphoma development in the viscera and musculature, and blindness in chickens (Davison and Nair, 2004; Jarosinski et al., 2006). The disease is caused by Marek's disease virus (MDV) belonging to the family Herpesviridae under the genus Mardivirus. MD has been successfully controlled by vaccination during the last decades (Churchill et al., 1969; Rispens et al., 1972). However, it is still a matter of great concern for the poultry industry because often the efficacy of MD vaccines is compromised by the constant evolution of MDV towards greater virulence (Witter, 1997). In addition to the evolution of MDV, other factors may reduce the efficacy of MD vaccines. Problems associated with the handling and storing of MD vaccines, early challenge of MDV in the farm, and co-infection with other immunosuppressive agents can greatly decrease the efficacy of MD vaccines. As a result, there are still sporadic outbreaks of MD that cause significant economic losses.

Marek's disease is prevalent in Bangladesh (Mosleuddin and Dewan, 1974; Suma et al., 2017). While histopathology is the gold standard for the diagnosis of MD, advanced techniques of plaque assay and real-time PCR are also used for the diagnosis of MD and monitoring of MDV vaccines (Abdul-Careem et al., 2006; Islam

*Corresponding author:- E-mail: mrislam_bau@yahoo.com

DOI: https://doi.org/10.3329/bvet.v35i1-2.53381 
et al., 2004; Baigent et al., 2005; Cortes et al., 2011). However, in Bangladesh, the diagnosis of MD is largely dependent on clinical and necropsy findings, which greatly vary among different outbreaks and is often confused with other lymphoproliferative diseases. The present study was designed to adopt a PCR technique for the molecular detection of MDV. Besides, we investigated the suitability of feathers, peripheral blood and spleen tissue for the molecular detection of MDV from field outbreaks.

\section{Materials and Methods}

\section{Samples}

We received sick or dead birds for investigation from 10 suspected outbreaks of Marek's disease in commercial layer farms of Mymensingh, Tangail, Gazipur and Pabna districts from March to December 2011. All the birds were reportedly vaccinated against MD at the hatchery at day-old with HVT vaccine. The age of the chickens was 8 to 35 weeks. Most of the affected birds showed anorexia, progressive emaciation, lameness, paralysis and twisted neck. Primary diagnosis of Marek's disease was made on the basis of typical clinical signs, necropsy findings and histopathology (Suma et al., 2017). A total of 24 samples (10 feather follicles, 8 blood samples and 6 spleens) of MD suspected sick or dead chickens were available. A live vaccine containing Serotype 1 MDV strain CVI 988 (Rispens) (Merial Ltd, France, marketed by Advance Animal Science Company Bangladesh Ltd., Dhaka) was used as the positive control.

\section{DNA extraction}

DNA from clinical samples and the vaccine virus was extracted by conventional phenol-chloroform-isoamyl alcohol method. For that, approximately $200 \mathrm{mg}$ of tissue (the proximal end of the feather shaft or a part of the spleen) or $200 \mu \mathrm{l}$ of buffy coat cells was taken in an Eppendorf tube, mixed with $200 \mu$ lof digestion buffer and $2 \mu 1$ of proteinase $\mathrm{K}$ to prepare a digestion mixture. The samples were digested overnight at $56^{\circ} \mathrm{C}$ with shaking on a thermo block. On the next day, $400 \mu \mathrm{l}$ of phenol-chloroformisoamyl alcohol was added to the digestion mixture, mixed with vigorous vortexing and incubated on ice for 2 minutes. The mixture was then centrifuged at $15000 \mathrm{rpm}$ for 5 minutes at $4{ }^{\circ} \mathrm{C}$ and the supernatant was collected in a fresh Eppendorf tube. Again $400 \mu \mathrm{l}$ of phenol-chloroform-isoamyl alcohol was added to the tube and centrifuged as above to collect the supernatant. The supernatant was transferred to $95 \%$ ethanol and $3 \mathrm{M}$ sodium acetate solution @ 2.5 times and $1 / 10^{\text {th }}$ of the supernatant volume, respectively and centrifuged at $13000 \mathrm{~g}$ for 5 minutes. The supernatant was discarded, and the DNA pellet was washed twice with $500 \mu \mathrm{l}$ of $70 \%$ ethanol by centrifugation as above. The DNA pellet was dried at $37^{\circ} \mathrm{C}$ on a thermo block. Finally, the DNA pellet was reconstituted in $50 \mu \mathrm{l}$ of nuclease-free water and stored at $-20^{\circ} \mathrm{C}$.

\section{Molecular detection of the virus}

The PCR protocol for the detection of MDV was adopted from published literature (Silva, 1992). PCR was carried out using the PCR Master Mix kit (Promega 
Corporation, WI, USA) as per the manufacturer's instruction. The extracted DNA was used as a template to amplify 132 base pair tandem repeats in the 'internal repeat long' of the MDV genome using the primer pair Oligo 1 (5'-TGCGATGAAAGTGCTA TGGAGG-3') and Oligo 2 (5'-GAGAATCCCTATGAGAAAGCGC-3') as described by Silva (1992). The thermal profile was as follows: initial denaturation at $95^{\circ} \mathrm{C}$ for $2 \mathrm{~min}$, followed by 35 cycles of PCR consisting of denaturation at $94^{\circ} \mathrm{C}$ for $1 \mathrm{~min}$, annealing at $55^{\circ} \mathrm{C}$ for $1 \mathrm{~min}$, and extension for $3 \mathrm{~min}$ at $72^{\circ} \mathrm{C}$, followed by final elongation for 5 $\min$ at $72^{\circ} \mathrm{C}$. The amplified products were visualized by electrophoresis using $1.4 \%$ agarose gel and the image was documented and stored in a computer.

\section{Results and Discussion}

\section{Adoption of PCR for the molecular detection of MDV}

The PCR thermal profile originally suggested by Silva (1992) successfully amplified MDV DNA. On electrophoresis, two strong bands of expected 185 and $317 \mathrm{bp}$, flanking one or two 132-bp tandem repeats, respectively, were observed. In addition, several weak bands of larger sizes, containing multiple repeats, were also observed (Fig. 1).

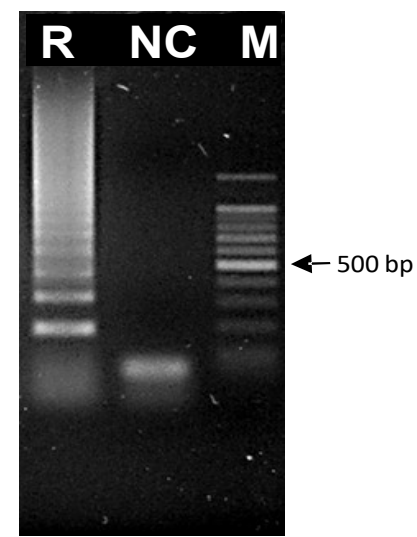

Fig. 1. Amplification of $132 \mathrm{bp}$ tandem repeats of Marek's disease virus from Rispens vaccine. M: 100 bp DNA ladder NC: Negative control. R: Rispens vaccine.

\section{Suitability of clinical specimens for molecular detection of MDV}

Next, we studied which clinical specimens produced the best results during molecular detection of the MDV. For that, we examined 24 clinical samples including 10 feather follicles, 8 buffy coats and 6 spleen samples from 10 suspected MD outbreaks. The results are presented in Fig. 2 and summarized in Table 1 . The eight buffy coat samples were all $(100 \%)$ positive in PCR (Fig. 2a). Of the 10 feather follicles, 7 (70\%) produced positive amplification of the MDV genome (Fig. $2 b$ ). Four of the six spleen tissue samples (67\% produced positive amplification of MDV in PCR (Fig. 2c). Taken together, buffy coat samples appeared to be the most suitable for molecular detection of the MDV from clinical specimens, followed by feather samples. However, Cortes 
et al (2011) observed that for the detection of serotype $1 \mathrm{MDV}$, solid tumor tissues and feathers were more suitable than blood.
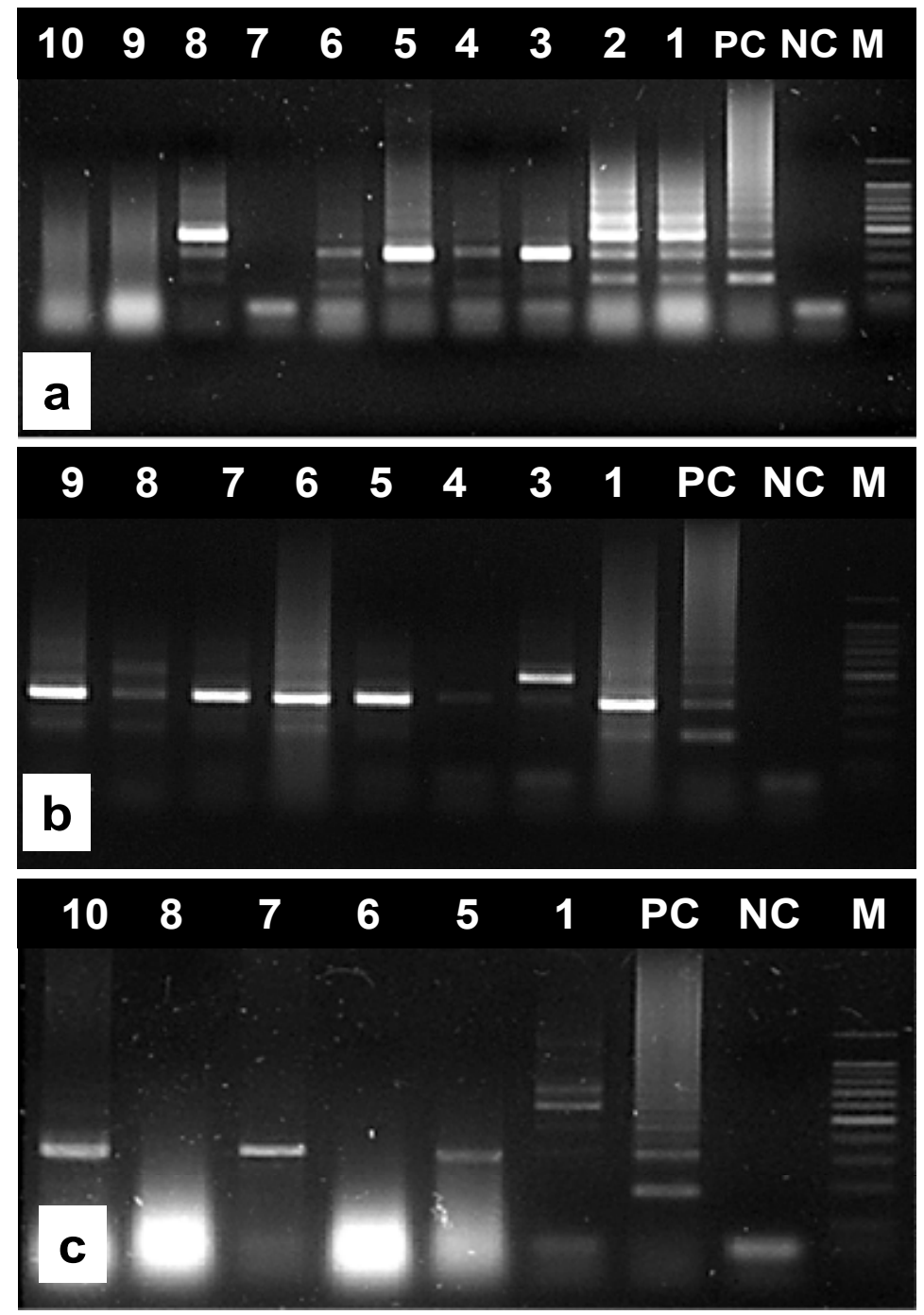

Fig. 2. Amplification of $\mathbf{1 3 2} \mathrm{bp}$ tandem repeats of Marek's disease virus from feather follicle (a), buffy coats (b) and spleen samples (c). M: 100 bp DNA ladder, NC: Negative control, PC: Positive control (Rispens), 1 to 10: samples.

The number of bands observed on electrophoresis in the PCR products varied between samples. One band of $317 \mathrm{bp}$ size was found in all positive samples. A few samples also yielded additional bands of $185 \mathrm{bp}$ size and/or multiple bands larger than $317 \mathrm{bp}$ size along with a smear at a higher molecular weight position. The primers used in this study amplify $132 \mathrm{bp}$ repeat sequences in the 'internal repeat long region' of the MDV genome. Virulent MDV field strains usually contain one or two repeats, while the attenuated strains of MDV have multiple repeats (Silva 1992). 
Thus the PCR protocol based on the abundance of $132 \mathrm{bp}$ repeats has been used to differentiate attenuated strains from the virulent strains (Becker et al., 1992; Zhu et al., 1992; Davidson et al., 1995). In the present study, all the samples were collected from clinically affected birds with a history of MDV vaccination; hence it is very likely that both vaccine virus and the field virus were detected in the PCR. This situation demands the development of a PCR protocol that would specifically detect the virulent MDV only.

Table 1: Summary of results of PCR for MDV on feather, buffy coat and spleen samples from clinical cases

\begin{tabular}{l|c|c|c}
\hline Case No. & Feather & Buffy coat & Spleen \\
\hline 1 & + & + & + \\
2 & + & ND & ND \\
3 & + & + & ND \\
4 & + & + & ND \\
5 & + & + & + \\
6 & + & + & + \\
7 & - & + & - \\
8 & + & + & - \\
9 & - & + & ND \\
10 & - & ND & + \\
\hline Total (positive/tested) & $7 / 10$ & $8 / 8$ & $4 / 6$ \\
\hline
\end{tabular}

Note: 'ND': Note done

In summary, the PCR protocol developed by Silva (1992) was successfully used for the detection of MDV in clinically affected birds. The possible presence of both virulent MDV and the vaccine virus in the samples was reflected by variable electrophoretic patterns of the PCR products, which limits the use of this PCR protocol in the situation where MDV infection occurs in chickens despite vaccination. Therefore, a PCR protocol is required that would exclusively detect virulent MDV. In our study, the buffy coat extracted from the blood samples appeared to be the most suitable followed by the feathers and spleen. Therefore, if live birds are submitted for investigation, peripheral blood samples as well as feathers should be collected for PCR. In case of dead birds, feathers may be the sample of choice.

\section{References}

Abdul-Careem MF, Hunter BD, Nagy E, Read LR, Sanei B, Spencer JL, Sharif S 2006: Development of a real-time PCR assay using SYBR Green chemistry for monitoring Marek's disease virus genome load in feather tips. Journal of Virological Methods $\mathbf{1 3 3}$ 34-40.

Baigent SJ, Petherbridge LJ, Howes K, Smith LP, Currie RJ, Nair VK 2005: Absolute quantitation of Marek's disease virus genome copy number in chicken feather and lymphocyte samples using real-time PCR. Journal of Virological Methods 123 53-64. 
Becker Y, Asher Y, Tabor E, Davidson I, Malkinson M, Weisman Y 1992: Polymerase chain reaction for differentiation between pathogenic and non-pathogenic serotype 1 Marek's disease virus (MDV) and vaccine viruses of MDV-serotypes 2 and 3. Journal of Virological Methods 40 307-322.

Churchill AE, Payne LN, Chubb RC 1969: Immunization against Marek's disease using a live attenuated virus. Nature 221 744-747.

Cortes AL, Montiel ER, Lemiere S, Gimeno IM 2011: Comparison of blood and feather pulp samples for the diagnosis of Marek's disease and for monitoring Marek's disease vaccination by real time-PCR. Avian Diseases 55 302-310

Davison F, Nair VK, Eds. 2004: Marek's disease: An Evolving Problem. Elsevier Press, Amsterdam. The Netherlands and Boston, USA.

Davidson I, Borovskaya A, Peri S, Malkinson M 1995: Use of the polymerase chain reaction for the diagnosis of natural infection of chickens and turkeys with Marek's disease virus and reticuloendotheliosis virus. Avian Pathology 24 69-94.

Islam A, Harrison B, Cheetham BF, Mahony TJ, Young PL, Walkden-Brown SW 2004: Differential amplification and quantitation of Marek's disease viruses using real-time polymerase chain reaction. Journal of Virological Methods 119 103-113.

Jarosinski KW, Tischer BK, Trapp S, Osterrieder N 2006: Marek's disease virus: lytic replication, oncogenesis and control. Expert Rev. Vaccines 5 761-72.

Moslehuddin, Dewan ML 1974: Incidence and diagnosis of Marek's disease in two poultry farms of Bangladesh. Bangladesh Veterinary Journal 8 45-48.

Rispens BH, Van Vloten J, Mastenbroek N, Maas HJL, Hendrick JL 1972: Control of Marek's disease in the Netherlands. II. Field trials on vaccination with an avirulent strain (CVI 988) of Marek's disease virus. Avian Diseases 16 126-138.

Silva RF 1992: Differentiation of pathogenic and non-pathogenic serotype 1 Marek's disease viruses (MDVs) by the polymerase chain reaction amplification of the tandem direct repeats within the MDV genome. Avian Diseases 36 521-528.

Suma U, Rahman M, Nooruzzaman M, Chowdhury E, Islam M 2017: Pathology of Marek's disease in layer chickens in Bangladesh. Bangladesh Veterinarian 34 35-41.

Witter RL 1997: Increased virulence of Marek's disease virus field isolates. Avian Diseases 41 149-163.

Zhu G-S, Ojima T, Hironaka T, Ihara T, Mizukoshi N, Kato A, Ueda S, Hirai K 1992: Differentiation of oncogenic and non-oncogenic strains of Marek's disease virus type 1 by using polymerase chain reaction DNA amplification. Avian Disease, 36 637-645. 